\title{
DERECHOEIECTORAL
}

\section{Elección de autoridades municipales en Costa Rica*}

\author{
Héctor Fernández Masís**
}

\section{f}

DOI 10.35242/RDE_2019_27_3

\section{Nota del Consejo Editorial}

Recepción: 24 de agosto de 2018.

Revisión, corrección y aprobación: 9 de octubre de 2018.

Resumen: Las elecciones de autoridades municipales completamente separadas de las elecciones de presidente, vicepresidentes y diputados se celebraron por primera vez en febrero de 2016, ya que en las realizadas durante los años 2002, 2006 y 2010 los puestos que se eligieron fueron los de alcaldes, vicealcaldes, síndicos, concejales de distrito, intendentes, viceintendentes y concejales municipales de distrito. El artículo ofrece un breve repaso por los antecedentes de las elecciones municipales y explica el sistema de asignación de plazas según el sistema de cociente y residuo.

Palabras clave: Elecciones municipales / Puestos de elección popular / Sistema de elección de alcaldes /Sistema de elección de regidores / Elección por cociente y residuo / Cociente electoral / Subcociente electoral.

Abstract: The election of municipal authorities completely apart from the elections for president, vice-presidents, and congress members took place for the first time in February 2016 since in the ones that took place in 2002, 2006 and 2010 the posts up for election were for mayor, deputy mayor, municipal trustee, district council, superintendent, deputy superintendent, and district municipal trustees. The article offers a brief review of the background of municipal elections and it explains the post appointment system according to the quotient and remainder system.

Key Words: Municipal elections / Popular election posts / System of election of Mayors / System of election of municipal trustee / Election by quotient and remainder / Electoral quotient / Electoral sub-quotient.

\footnotetext{
* Texto base de la Serie para Entender $n .^{\circ} 5$ de la Editorial del Instituto de Formación y Estudios en Democracia. ** Costarricense, abogado, hfernandez@tse.go.cr. Licenciado en Derecho por la Universidad de Costa Rica. Egresado del Plan de Estudios del Doctorado Académico en Derecho Público de la Universidad Escuela Libre de Derecho. Especialista en Derecho Público por el Sistema de Estudios de Posgrado de la Universidad de Costa Rica. Director general del Registro Electoral y de Financiamiento de Partidos Políticos del Tribunal Supremo de Elecciones de Costa Rica (TSE).
} 


\section{DERECHO ELECTORAL}

\section{Relevancia del tema}

El Tribunal Supremo de Elecciones fue creado por la Constitución Política de 1949 como responsable, exclusivo e independiente, de la organización, dirección y vigilancia de los actos relativos al sufragio. La primera elección que organizó ese supremo organismo electoral fue la de 1953, donde los costarricenses votaron para elegir los cargos a la presidencia y vicepresidencias de la República, diputados a la Asamblea Legislativa, regidores municipales y síndicos distritales. Esas mismas autoridades se continuaron eligiendo, de 1958 hasta 1998, en un mismo evento comicial, que se llevó a cabo de manera cuatrienal los primeros domingos de febrero del año en que debía verificarse la renovación de dichas autoridades. En todas esas elecciones, la atención de la gran mayoría de los ciudadanos se centraba en los puestos a nivel nacional, lo que era lógico porque la propaganda política y las informaciones periodísticas giraban, fundamentalmente, en torno a los candidatos propuestos para esos cargos, por lo que los nombres de las personas que se postulaban para puestos a nivel local pasaban casi inadvertidos, a pesar de que aportaban un trabajo importante en sus comunidades para llevar votos al partido que los propuso.

En el período comentado, cada persona que concurría a emitir su voto recibía tres papeletas, una para presidente y vicepresidentes, otra para diputados y la última para los cargos de regidores y síndicos municipales. Esos eran los únicos puestos de elección popular que existían y la consigna por parte de las agrupaciones partidarias era lograr que las personas votaran por el mismo partido en todas las papeletas. Obviamente, el nombre que más salía a relucir era el del candidato a la presidencia de la República. Los votos para los cargos municipales casi eran por arrastre, para completar el proceso de votación, pero sin tener plena conciencia de quiénes se postulaban para esos puestos.

Precisamente, una de las motivaciones y justificaciones para lograr que las elecciones a nivel local se hicieran separadas de las de cargos a nivel nacional fue poder visibilizar a quienes pretendían ocupar esos cargos en el siguiente período, pues de esa forma podrían realizar su propaganda política sin competir con candidaturas de presidente o diputados, y los electores podrían valorar sus capacidades y propuestas a la hora de decidir su voto. Asimismo, se proponía ampliar la cantidad de cargos por elegir a nivel municipal, para también brindar a los electores la oportunidad de escoger al funcionario ejecutivo de las municipalidades, cuyo nombramiento, hasta ese momento, era potestad de los concejos municipales. 


\section{DERECHO ELECTORAL}

Las gestiones que por décadas se venían haciendo tuvieron sus frutos con la aprobación del Código Municipal en 1998, donde no solo se dispuso realizar la elección de cargos municipales separada de la nacional, sino que además estableció la elección popular del funcionario ejecutivo a que hace referencia el artículo 169 de la Constitución Política, que a partir de ese momento se denominaría alcalde municipal, así como de los miembros de los concejos de distrito, que también eran designados por los regidores. En este último caso, así mismo, esa nueva legislación contempla a los concejos municipales de distrito, órgano que solo existe en ocho distritos, así como al funcionario ejecutivo de estos, al que se le llama intendente.

En un primer momento, del año 2002 al 2010, la elección de los alcaldes, concejales y síndicos se realizaba el primer domingo de diciembre del mismo año en que se elegían las autoridades nacionales, pero los regidores municipales se siguieron eligiendo en febrero, junto con los cargos de presidente y diputados. Fue con la promulgación del nuevo Código Electoral de 2009 que se consolidaron las reformas a la legislación municipal para pasar las elecciones de todos los cargos a nivel local a medio período de las nacionales: ello sucedió por primera vez en febrero de 2016.

Es indudable el peso y la importancia de las autoridades municipales en nuestro sistema democrático, por el impacto de su gestión en el bienestar de la ciudadanía; de ahí que es un deber de todos conocer cuáles son los puestos de elección popular que existen a escala cantonal y distrital y cómo se eligen, para tomar conciencia de nuestro poder como ciudadanos, en la escogencia de las personas que consideremos más aptas para desempeñar cada uno de esos cargos, y la responsabilidad que ello conlleva, ya que independientemente de la cantidad de personas que acudan a las urnas, las decisiones de quienes resulten electos afectarán a todos los habitantes de esas comunidades. Por eso, quienes se abstienen de ir a votar no solo renuncian a ejercer ese poder, sino que dejan en manos de otros esa decisión fundamental para la vida comunitaria.

\section{ANTECEDENTES DE LAS ELECCIONES MUNICIPALES}

La Constitución Política de 1949, además de crear el Tribunal Supremo de Elecciones (TSE), estableció una serie de normas fundamentales para garantizar la transparencia y pureza del sufragio. En lo que se refiere al régimen municipal, de conformidad con los artículos 169 y 171 de dicha carta magna, los regidores municipales son funcionarios de elección popular y serán elegidos por cuatro años, mientras que el numeral 172 -antes de la reforma introducida por Ley 8105 del 31 de mayo de 2001-indicaba que 


\section{DERECHO EIECTORAL}

cada distrito estaría representado ante la municipalidad por un síndico propietario y su respectivo suplente, norma que fue complementada por el artículo 65 del Código Municipal de 1970 (Ley 4574 y sus reformas) que disponía que estos serían de elección popular. Hasta 1998, esos eran los únicos cargos de elección popular que existían a escala municipal y será en diciembre de 2002 cuando por primera vez la ciudadanía podrá elegir a los alcaldes, síndicos y concejales a nivel distrital e intendentes; solo los regidores fueron electos en febrero de ese año.

A partir de la creación del Instituto de Fomento y Asesoría Municipal (IFAM) en 1971, empezó a crecer la propuesta de realizar elecciones municipales en forma separada de las nacionales, cuyo principal argumento era que la población no prestaba mayor atención a las candidaturas locales, ya que estas quedaban subsumidas en las campañas partidarias marcadas por las elecciones presidenciales (Rodríguez y Zeledón, 2003, p. 15). Otro argumento en favor de esa separación era que ello formaba parte de una estrategia para el fortalecimiento de las municipalidades, a través de un proceso de descentralización que promoviera espacios democráticos mediante los cuales se viera fortalecida la representación popular y el acceso al poder político de la ciudadanía (Mora, 1999, p. 79).

Desde 1993 un grupo de instituciones sumaron esfuerzos e intereses en función de la reforma al régimen municipal, con el objetivo de mejorar la calidad del marco descentralizador (Zeledón, 2003, p. 61). Sobre este particular, el TSE, en su resolución n. ${ }^{\circ} 405-E 8-2008$ del ocho de febrero de dos mil ocho, señaló que en las décadas subsiguientes a la promulgación de la Constitución de 1949 se había venido incrementando la actividad legislativa tendiente a descentralizar el poder político, en virtud de lo cual se gestaron las reformas a los artículos 170 y 172 constitucionales, y en las postrimerías del siglo veinte se había perfilado una política general del Estado encaminada a asignar mayores competencias y recursos a las municipalidades, donde el fortalecimiento de los municipios se ha comprendido como un factor clave para la profundización democrática.

Dentro de las acciones concretas tendientes a apuntalar la mencionada estrategia de fortalecimiento de los municipios, sin duda un hito importante fue la promulgación de un nuevo código municipal en el año 1998, mediante Ley 7794 publicada en La Gaceta n. ${ }^{\circ} 94$ del 18 de mayo de ese año, que sustituyó al anterior vigente desde 1970. Dentro de las innovaciones que nos interesa destacar, y que incluso se dice que es la más importante en términos de participación ciudadana en el ámbito municipal, está el incremento de los cargos de elección popular y convertir el antiguo ejecutivo 


\section{DERECHO ELECTORAL}

municipal, designado por el concejo municipal, en el cargo de alcalde, elegido de manera directa por la ciudadanía y en comicios autónomos (Sobrado, 2011, p. 145).

Esta nueva normativa no solo reformó la figura del funcionario ejecutivo referido en el artículo 169 constitucional, denominándolo alcalde y el establecimiento de la instancia de elección directa para esta autoridad (Rodríguez y Zeledón, 2003, p. 11), sino que además dispuso la creación de dos cargos de alcalde suplente, también de elección popular, y señaló que los concejales de distrito, tanto propietarios como suplentes, que anteriormente eran designados por los respectivos concejos municipales, serían de elección popular. Finalmente, en lo que resulta de interés para el tema que estamos desarrollando, es importante resaltar que la citada Ley 7794 también reformó el Código Electoral, a los efectos de que esos nuevos cargos se eligieran en forma separada de los cargos de presidente, diputados y regidores, concretamente el primer domingo de diciembre del año en que debía renovarse la Presidencia de la República y la Asamblea Legislativa, en virtud de lo cual dispuso que el TSE realizara la convocatoria de esas elecciones municipales el primero de agosto anterior y que quienes resultaran electos entrarían en posesión de sus cargos el primer lunes de febrero siguiente a la elección.

De esta suerte, con el Código Municipal de 1998 se instauran por primera vez las elecciones municipales separadas de las nacionales. Sin embargo, en esa separación no se incluyeron todos los cargos a nivel local, pues los regidores siempre debían elegirse junto con el presidente y los diputados. Ello por cuanto la reforma político-electoral de 1998 quedó inserta en otro conjunto de reformas institucionales que buscaban la descentralización estatal, razón por la cual el proyecto se gesta en la Comisión de Asuntos Municipales de la Asamblea Legislativa y no en la de Asuntos Electorales, lo que limitó la reforma a aspectos contenidos en el Código Municipal y por ello, la elección de alcaldes quedó desfasada de la elección de regidores y restringida para realizarse en el mismo año de las elecciones presidenciales (Rodríguez y Zeledón, 2003, p. 15). Por otro lado, tampoco el mencionado código señaló en forma clara y precisa cuándo debían elegirse los síndicos distritales, por lo que el TSE debió acudir a su facultad de intérprete de las disposiciones legales en materia electoral (artículo 102 inciso 3 de la Constitución Política) y mediante resolución n. ${ }^{\circ} 1734-\mathrm{E}-2001$ del veinticuatro de agosto del dos mil uno, interpretó los artículos 55 y transitorio II de la referida legislación, así como el numeral 98 del Código Electoral dispuso, en lo conducente, que: 


\section{DERECHO ELECTORAL}

a pesar de que el artículo 55 del Código Municipal no establece en forma expresa y clara que la elección de los síndicos debe verificarse junto con la elección de alcaldes, no cabe duda que la reforma del artículo 97 del Código Electoral tuvo como propósito que los representantes distritales previstos en el artículo 172 constitucional deban elegirse en forma simultánea con los cargos de elección popular creados por el nuevo Código Municipal, sean los alcaldes y miembros de los concejos de distrito, ello a pesar de que el artículo 98 del Código Electoral establece que la elección de los síndicos municipales debe verificarse el primer domingo de febrero del año en que debe venir la renovación, entre otros, del Presidente y Vicepresidentes de la República, artículo que también deberá entenderse que ha sido modificado, pues de acuerdo con los principios hermenéuticos, toda norma posterior deroga o modifica las anteriores que se le opongan.

Agrega el fallo comentado que:

A juicio de este Tribunal, teniendo en cuenta que el propio legislador dispuso que los síndicos formen parte de los concejos de distrito y que la convocatoria a elecciones para ambos puestos se verifique el mismo día, lo procedente es aclarar dicha contradicción normativa interpretando que tanto concejales como síndicos entrarán en posesión de sus cargos en forma simultánea, a los efectos de que estos últimos puedan iniciar su labor como miembros integrantes de los concejos de distrito, desde el primer día de funciones de este órgano.

Es así como las primeras elecciones municipales separadas de las nacionales quedaron fijadas para celebrarse el primer domingo de diciembre del año 2002, fecha en la cual se debía elegir a los alcaldes municipales y sus respectivos suplentes en todos los cantones del país, así como los síndicos, concejales de distrito y concejales municipales de distrito, tanto propietarios como suplentes, y a los intendentes, que son los funcionarios ejecutivos de estos últimos órganos. Esta elección, además, implicaba en sí misma una novedad a nivel de la logística que debía realizar el TSE para organizar ese proceso electoral, pues sería la primera vez que habría elecciones en la circunscripción territorial más pequeña del país, como son los distritos administrativos. 


\section{DERECHO ELECTORAL}

\section{LAS PRIMERAS ELECCIONES MUNICIPALES}

Resulta paradójico que teniendo nuestro país la democracia más longeva de toda Latinoamérica, fuimos los últimos en esta región que realizamos en forma directa las elecciones para alcaldes (Rodríguez y Zeledón, 2003, p. 5). Tal como se mencionó anteriormente, fue en el mes de diciembre del año 2002 cuando por primera vez los alcaldes fueron electos, junto con los restantes cargos de elección popular a nivel municipal -salvo los regidores-, constituyéndose en las primeras elecciones de cargos municipales separadas de las nacionales. Ese año también establece otro hito en la historia electoral del país, no solo por ese hecho, sino porque, además, fue la primera ocasión, desde que entró en vigencia la actual Constitución Política, en que fue necesario definir los cargos de presidente y vicepresidentes de la República en una segunda vuelta de elección, debido a que ninguno de los partidos que propuso candidatos para esos cargos logró superar el $40 \%$ de los votos válidamente emitidos, por lo que de conformidad con lo dispuesto por el artículo 138 constitucional, las dos nóminas más votadas debieron participar en esa segunda elección popular el primer domingo de abril siguiente. En consecuencia, ese año -2002- se llevó a cabo una elección nacional el primer domingo de febrero, una segunda elección presidencial el primer domingo de abril y las primeras elecciones municipales el primer domingo de diciembre, tres procesos electorales un mismo año, algo inédito para el TSE ${ }^{1}$.

En esas primeras elecciones municipales se eligieron 81 alcaldes, 162 alcaldes suplentes, 464 síndicos propietarios e igual cantidad de suplentes, 1828 concejales de distrito propietarios e idéntica cantidad de concejales suplentes, 32 miembros propietarios y suplentes de 8 concejos municipales de distrito, así como sus 8 respectivos intendentes, lo que representó un total de 4900 cargos de elección popular.

Solo en dos ocasiones más las elecciones municipales se realizaron en diciembre del mismo año en que debía efectuarse la renovación de los cargos de presidente y diputados, específicamente en diciembre de 2006 y diciembre de 2010. Sin lugar a dudas, el cargo que más concentraba la atención de los partidos políticos y ciudadanos en esos tres primeros comicios municipales era el de alcalde que, anteriormente y bajo la denominación de ejecutivo municipal, era designado por el respectivo concejo. Es decir, antes de diciembre de 2002 los electores del cantón

\footnotetext{
${ }^{1}$ Por si fuera poco, en diciembre de 2002 debió suspenderse la elección en diez cantones de la vertiente atlántica azotados por fuertes aguaceros debido a un fenómeno atmosférico; estas se reprogramaron para enero de 2003.
} 


\section{DERECHO ELECTORAL}

carecían de mecanismos directos para incidir en los nombramientos o las gestiones de los ejecutivos, toda vez que su rendición de cuentas era ante el concejo (Rodríguez y Zeledón, 2003, p. 9), ya que solo los regidores estaban facultados para nombrar y remover a los ejecutivos, así como también a los concejales de distrito, pues solo el síndico distrital era de elección popular. Pero con el nuevo Código Municipal se traslada a la ciudadanía local el derecho de nombrar a sus representantes municipales (cantonales y distritales) de manera directa. En la exposición de motivos para justificar la elección directa y por sufragio popular del alcalde, la Comisión de Reforma al Régimen Municipal señaló:

Se propone transformar el actual Ejecutivo, de elección del Concejo, a un alcalde de elección popular. Dicha elección se hará en la misma fecha en que se renueva el concejo, y los vecinos del cantón votarán por una fórmula que contenga los nombres de un alcalde y un vicealcalde. El alcalde será pues de origen electoral, por un plazo de cuatro años. Se propone no prohibir la reelección en dicho cargo para generar una experiencia administrativa y continuidad de las labores. (Mora, 1999, p. 83).

Así las cosas, un efecto de la nueva legislación es que la estabilidad de quienes ocupen las alcaldías no va a depender de los regidores y regidoras, como sucedía en el pasado con los ejecutivos municipales; sino que al ser electos popularmente y con un mandato que abarca cuatro años con la posibilidad de reelección, como fue aprobado, la continuidad en dicho cargo va a depender exclusivamente de los electores, quienes le podrán negar el voto para que siga en el puesto si se presenta como candidato para reelegirse, o bien, su mandato puede ser revocado con base en lo dispuesto por el artículo 19 del Código Municipal, en virtud del cual los electores pueden ser convocados a una consulta popular, denominada plebiscito, para decidir mediante su voto si se destituye o no al alcalde ${ }^{2}$. Es por ello que a partir del 2002, quienes resulten alcaldes gozan de una mayor seguridad y estabilidad laboral, pues el origen electoral de su nombramiento atenúa las potestades de remoción y de sanción que anteriormente ejercía el concejo

\footnotetext{
2 En nuestro ordenamiento jurídico electoral, solo a los alcaldes se les puede revocar el mandato, pues esa posibilidad no existe para ningún otro cargo de elección popular, al igual que solo los alcaldes pueden ser reelectos de manera sucesiva, sin que se limite la cantidad de veces que pueden optar por la reelección. Sin embargo, esa revocatoria de mandato, por la forma en que está concebida, es para casos excepcionales, pues requiere que la convocatoria al respectivo plebiscito sea acordada por las tres cuartas partes de los regidores integrantes del concejo, y que los votos necesarios para su destitución sumen al menos los dos tercios de los emitidos en el plebiscito, suma que tampoco puede ser inferior al $10 \%$ de los electores inscritos en el cantón, requisitos que no son fáciles de cumplir. De hecho, desde que está vigente el Código Municipal solo en una ocasión se ha revocado el mandato de un alcalde y fue en el cantón Pérez Zeledón en el año 2011, pero ese sólo caso revela que ello es posible y que solo está en manos de los electores la continuidad del alcalde en su puesto.
} 


\section{DERECHO ELECTORAL}

municipal sobre el ejecutivo, quien invertía gran parte de su tiempo en defender su puesto (Mora, 1999, p. 85).

En consecuencia, este nuevo procedimiento para la elección del funcionario ejecutivo de las municipalidades también tiene el efecto de descentralizar el poder del Gobierno central hacia los Gobiernos municipales, con el propósito de incentivar la participación y decisión popular a la hora de elegir a las autoridades locales por medio del sufragio (Aguilar, 2000, p. 38). Además, jurídicamente se delega en los partidos políticos la responsabilidad de establecer y aplicar los procedimientos o mecanismos necesarios con el propósito de garantizarle al electorado la idoneidad de los candidatos propuestos para todos estos cargos (Aguilar, 2000, p. 158); ya que el Código Municipal también reformó el artículo 5 del Código Electoral vigente al momento de su promulgación, no solo para incluir en el primer párrafo a estos nuevos cargos municipales de elección popular, sino que en el segundo párrafo advierte a los partidos que son responsables de que la elección de estos funcionarios recaiga sobre personas de reconocida idoneidad, con el fin de garantizar al pueblo la capacidad de sus gobernantes. Si bien la democracia representativa se ensancha con la elección directa de estas autoridades locales, es lo cierto que al mismo tiempo surge también la responsabilidad de los partidos políticos de presentar a la ciudadanía un programa de gobierno local, lo que introduce la figura del voto programático a nivel local, mecanismo ausente en anteriores elecciones de autoridades municipales, donde predominaba la tradición del voto en "línea vertical" con una enorme dosis de desconocimiento (Zeledón, 2003, p. 70).

En suma, aparte de las alcaldías, los otros cargos por elegir en estas primeras elecciones municipales separadas eran los de concejales de distrito, junto con el síndico, además de los concejales municipales de distrito, figura presente solo en ocho distritos administrativos del país, donde también era necesario elegir al funcionario ejecutivo de ese órgano distrital, denominado intendente. Quienes resultaren electos en esos cargos tendrían más y mejor presencia en la generación y administración de propuestas y proyectos de desarrollo para cada distrito costarricense (Echeverría, 2013, p.6).

Al repasar las elecciones municipales celebradas hasta la fecha, se concluye que estas han incidido en un aumento de los partidos políticos inscritos a escala cantonal y, en ese sentido, implica una movilización cada vez mayor de ciudadanos interesados en postularse y -eventualmente- asumir un cargo público a lo interno de las corporaciones municipales (Retana, 2016, p. 148). 


\section{DERECHO EIECTORAL}

En efecto, en el año 2002 participaron 34 agrupaciones políticas: 10 partidos nacionales, 4 provinciales, 19 cantonales y una coalición, mientras que para el año 2006 fue un total de 45 partidos políticos participantes: 13 nacionales, 7 provinciales y 25 cantonales. En 2010 hubo dos más y se llegó a 47 partidos: 9 nacionales, 5 provinciales y 26 cantonales. Para la última elección municipal (2016), la primera celebrada en el mes de febrero, fueron 62 las agrupaciones políticas participantes: 12 de nivel nacional, 4 provincial, 42 cantonal y 4 coaliciones también de nivel cantonal (Zamora, 2016, p. 63).

A pesar de ese aumento significativo en la cantidad de partidos participantes en las elecciones municipales, sobre todo en el nivel cantonal, interesa llamar la atención sobre el hecho de que todas las elecciones municipales se han caracterizado por una escasa participación ciudadana. Por ejemplo, en las tres primeras celebradas en el mes de diciembre, el abstencionismo en todos los cantones del país fue, en promedio, superior al 70\% del electorado; concretamente, en el 2002 fue de un 77,20\%; en el 2006 de un $76,16 \%$ y en el 2010 de un $72,11 \%{ }^{3}$. En otras palabras, aproximadamente solo tres de cada diez electores acudieron a las urnas en esos procesos, de suerte que quienes resultaron electos en los cargos en disputa obtuvieron un porcentaje de votos sumamente bajo como se presenta en la tabla 1, respecto a la cantidad de electores inscritos en su cantón o distrito administrativo. Así, por ejemplo, en las elecciones municipales celebradas en diciembre de los años 2002, 2006 y 2010 en los cantones centrales de las provincias que conforman la gran área metropolitana, los votos obtenidos por los alcaldes electos y su peso relativo respecto del total de electores inscritos en el cantón, así como el abstencionismo registrado en estos cantones fue el que se presenta en la tabla 1.

\footnotetext{
${ }^{3}$ Disponible en http://atlaselectoral.tse.go.cr
} 


\section{DERECHO EIECTORAL}

Tabla 1

Votos obtenidos en la elección de alcalde en los cantones centrales de las provincias del Valle Central, elecciones de 2002 a 2010

\begin{tabular}{l|r|r|r|r|r}
\hline Cantón & $\begin{array}{c}\text { Año de la } \\
\text { elección }\end{array}$ & \multicolumn{2}{|c|}{$\begin{array}{c}\text { Votos obtenidos } \\
\text { por el partido que } \\
\text { ganó la alcaldía }\end{array}$} & \multicolumn{2}{|c}{ Abstencionismo } \\
\cline { 3 - 6 } & 2002 & 12998 & 6,07 & 177638 & 82,90 \\
Central, San José & 2006 & 18061 & 8,07 & 197244 & 88,12 \\
& 2010 & 25206 & 11,18 & 184147 & 81,65 \\
\hline Central, Alajuela & 2002 & 11681 & 8.33 & 112072 & 79,96 \\
& 2006 & 13116 & 8,31 & 131239 & 83,14 \\
& 2010 & 16339 & 9,44 & 136539 & 78,86 \\
\hline Central, Cartago & 2002 & 6805 & 7,83 & 73680 & 84,77 \\
& 2006 & 10689 & 11 & 76182 & 78.41 \\
& 2010 & 12753 & 12,03 & 81438 & 76,82 \\
\hline Central, Heredia & 2002 & 2946 & 4,21 & 62246 & 88,90 \\
& 2006 & 6177 & 7,90 & 66574 & 85,12 \\
& 2010 & 9990 & 11,70 & $69952)$ & 81,95 \\
\hline
\end{tabular}

Nota: Elaborada con base en Atlas electoral

Téngase en cuenta que se trata de cantones con alta densidad de población, que tienen municipalidades importantes en términos de infraestructura, planilla y servicios que administran, donde existe en general un alto acceso de la ciudadanía a servicios públicos como educación y salud, y a distintos medios de información y; sin embargo, el índice de abstencionismo en todos los casos fue mayor al promedio. Resultados como los descritos motivaron la necesidad de plantear nuevas reformas para fortalecer la participación del electorado en estos procesos a nivel local. Como bien mencionó el magistrado presidente del TSE, reducir esos grados de apatía constituye uno de los mayores retos para una sociedad que hoy cuenta con canales de participación ciudadana que no existían hace tan solo 10 años. (Sobrado, 2011).

Dentro de los principales problemas de fondo identificados, que podían estar propiciando la baja participación en las citadas elecciones municipales, estaban la ausencia de financiamiento público, la separación de las elecciones de alcaldes de las de regidores y la relativa inactividad de estructuras partidarias, con lo que se privaba de su experiencia a los postulantes a las alcaldías. También podrían estar afectando el proceso 


\section{DERECHO ELECTORAL}

aspectos de carácter más coyuntural como la fecha de las elecciones (Rodríguez y Zeledón, 2003, p. 12).

En efecto, la fecha en que se celebraban esos comicios no era la más conveniente, ya que en diciembre la ciudadanía está más atenta al fin del curso escolar y colegial, pago de aguinaldos y compras de regalos de diciembre que a ir a votar; sin dejar de lado que es un mes donde frecuentemente se presentan temporales en la vertiente atlántica. Por otra parte, esa relativa inactividad de las estructuras partidarias puede tener su origen en dos situaciones; por un lado, al haber enfrentado las elecciones nacionales en febrero, para diciembre los partidos no tienen recursos ni medios adecuados para organizarse y asumir de la mejor forma sus campañas electorales a nivel cantonal, pues quienes tienen derecho a la contribución estatal, para el mes de agosto cuando se convocaban las elecciones municipales no habían recibido el reembolso correspondiente por su participación en las elecciones nacionales y tampoco había motivación para gestionar nuevos recursos, porque no estaba previsto ningún margen de financiamiento estatal para las elecciones municipales. Además, debido a que los regidores habían sido electos en febrero, quienes participaron como candidatos a esos puestos ya no tienen mucho interés de involucrarse ni aportar sus estructuras para trabajar en las elecciones municipales.

Finalmente, no debe pasarse por alto el hecho de que las elecciones municipales, sobre todo las del 2002 que fueron las primeras, se caracterizaron por un conocimiento relativamente bajo por parte de la ciudadanía, tanto del proceso electoral en sí como de la oferta electoral (Espinosa, Estrada, Gómez y Jiménez, 2003, p. 55).

En virtud de lo expuesto, se empezaron a delimitar los aspectos por reformar con miras a fortalecer las elecciones municipales, cuyo objetivo principal era lograr motivar una mayor participación ciudadana. En concreto, se planteó lo siguiente: dotar a estas elecciones de financiamiento estatal; que se celebraran en el mes de febrero, dos años después de las elecciones nacionales, con el propósito de que los partidos políticos tuvieran el tiempo suficiente para organizar sus estructuras en todos los cantones del país en que pretendían participar y conseguir los recursos financieros necesarios para afrontar el proceso, y trasladar la elección de regidores junto con los restantes cargos a nivel local; reforma que se empieza a gestar en el año 2007. 


\section{DERECHO ELECTORAL}

\section{MEJORAS inCORPORADAS A LAS ELECCIONES MUNICIPALES}

Hasta 2018 solo se han realizado cuatro elecciones municipales: muy pocas si tenemos en cuenta que el TSE ha organizado 17 comicios nacionales, de los cuales los de mayor abstencionismo fueron los de 1958 con un 35,3\% y 2006 con 34,8\%, ya que de 1962 a 1994 se mantuvo la participación en cifras muy cercanas al $80 \%$, con una reducción aproximada al $70 \%$ en las restantes, incluida la de $2018^{4}$, o lo que es lo mismo, el abstencionismo en las últimas décadas se ha mantenido en un rango cercano al $30 \%$. Sin embargo, en lo que se refiere a los procesos electorales a nivel municipal ha sucedido casi lo inverso, pues el abstencionismo superó el $70 \%$ en las elecciones de 2002, 2006 y 2010.

Como hemos apuntado, dentro de los principales problemas identificados en los comicios locales, estaban la fecha de su celebración, su falta de financiamiento y el hecho de que la elección de regidores se había mantenido en febrero junto con las elecciones presidenciales y legislativas, a pesar de que los demás cargos municipales, incluyendo el de alcalde, se elegían en el siguiente mes de diciembre. Es por ello que en el 2007 se aprueba otra reforma tendiente a solucionar lo relativo a la fecha de las elecciones, en virtud de lo cual se promulga la Ley 8611 del 12 de noviembre de 2007, publicada en La Gaceta n. ${ }^{\circ} 225$ del 22 de noviembre de 2007. Esta ley, además de reformar los artículos 19 y 20 del Código Municipal con el propósito de cambiar el nombre y las funciones de los alcaldes suplentes, que a partir de ese momento se denominan vicealcalde primero y vicealcalde segundo, con la particularidad de que el primero, aparte de la función de sustituir al alcalde durante sus ausencias, pasó a ser un funcionario permanente, con remuneración (Zamora, 2016, p. 49); también reforma el artículo 14 del mencionado código, con el objetivo de que la elección a nivel local se realice dos años después de la elección nacional.

Este cambio podría tener varios efectos positivos, entre ellos, que los partidos políticos y la ciudadanía tendrán dos años, después de las elecciones presidenciales, de preparación para las municipales, evitando con ello la sensación de "agotamiento electoral" que ha caracterizado a los comicios celebrados en diciembre (Sobrado, 2011, p. 146). Sin embargo, la nueva ley aprobada no dispuso nada en lo referente a los regidores, lo que produjo un vacío legislativo en cuanto a la fecha de elección de estos cargos, razón por la cual el TSE en la resolución n. ${ }^{\circ} 405-E 8-2008$ del ocho de

\footnotetext{
${ }^{4}$ Ver http://www.tse.go.cr/pdf/elecciones/eleccionescifras.pdf
} 


\section{DERECHO EIECTORAL}

febrero de dos mil ocho, nuevamente hace uso de su potestad constitucional e interpreta el artículo 14 reformado, y define que la elección de los regidores debía efectuarse junto con los demás cargos municipales y a medio período presidencial (Echeverría, 2016, p. 19).

La referida resolución también determinó que la elección conjunta de todos los cargos a nivel municipal, incluidos los de regidores, sería a partir de la elección municipal del 7 de febrero de 2016. Esto obviamente alteraba el ciclo electoral de las autoridades electas en 2010, que es de cuatro años; ya que por última vez los regidores se designarían en febrero de ese año y los restantes en diciembre, en virtud de lo cual la indicada resolución también dimensionó su aplicación en el tiempo, en el sentido de que los cargos municipales que se elegirían en diciembre de 2010 tendrían -por excepción- y con el fin de compatibilizar ese ciclo, un mandato de casi seis años, pues concluiría en abril del año 2016 (Zamora, 2016, p. 49).

Otro hecho que contribuyó a solucionar los problemas mencionados fue la aprobación por parte de la Asamblea Legislativa, el 11 de agosto de 2009, de la Ley 8765, publicada en el Alcance 37 a La Gaceta n. ${ }^{\circ} 171$ del 2 de setiembre de 2009, mediante la cual se promulgó un nuevo código electoral y, además, se reforma el Código Municipal, con el fin de fortalecer las elecciones municipales. Por un lado, en su artículo 390 aparte a) modifica nuevamente el artículo 14 del Código Municipal, producto de lo cual el último párrafo de ese numeral ya contempla de manera clara que todos los cargos de elección popular a nivel municipal serán elegidos el primer domingo de febrero, dos años después de las elecciones nacionales; en otras palabras, se lleva a rango de ley el contenido de la resolución 405 del TSE antes referida (Echeverría, 2016, p. 19). Además, en el capítulo relativo al régimen económico de los partidos políticos, se incluye en la sección segunda una norma que establece el deber del Estado de contribuir con un monto equivalente al cero coma cero tres por ciento $(0,03 \%)$ del Producto Interno Bruto (PIB), para cubrir los gastos en que incurran los partidos políticos por su participación en los procesos electorales de carácter municipal, siempre que cumplan los requisitos que la misma legislación establece para tener derecho a ello (artículo 91 del Código Electoral). Asimismo, se incluye una sección tercera (artículos del 99 al 102) donde se regula lo relativo a la contribución estatal para procesos electorales municipales.

Por otro lado, producto del Código Electoral de 2009, el proceso electoral municipal presenta también, como nueva condición, que las nóminas de candidatos deben observar los principios de paridad y alternancia en 


\section{DERECHO EIECTORAL}

materia de género (Sandí y Víquez, 2014, p. 64). La primera ocasión en que tales principios debieron ser cumplidos de cara a la inscripción de candidaturas fue en las elecciones municipales de 2010, pero obviamente no se aplicaron a la elección de regidores que se había llevado a cabo en febrero de ese año; por tal motivo, es en las elecciones de 2016 donde ya todas las nóminas de candidatos municipales a puestos de elección popular deben integrarse paritariamente, en cumplimiento del nuevo régimen (Zamora, 2016 p. 49), y de manera trenzada; es decir, hombre-mujerhombre o mujer-hombre-mujer, con lo cual se completa el ciclo de la primera puesta en marcha de ese nuevo régimen dispuesto en el artículo 148 del Código Electoral de 2009.

Las dos reformas comentadas solucionan los principales problemas que se apuntaban a las elecciones municipales, pues se les dota de financiamiento, se pasan a medio período y en el mes de febrero, que es cuando tradicionalmente se han celebrado las elecciones en Costa Rica, así como también se establece la obligación de que todos los cargos a nivel municipal se elijan el mismo día.

La primera elección donde todas las reformas referidas tuvieron plena vigencia fue la celebrada el 7 de febrero de 2016. En términos estadísticos, estos comicios presentan algunas diferencias que conviene destacar respecto de sus antecesores. En primer término, la participación aumenta en casi ocho puntos porcentuales, pues pasa de un $27,9 \%$ en el 2010 , a un $35,4 \%$ en 2016; dicho de otra manera, decrece el abstencionismo, al bajar de un $72,1 \%$ en la última elección celebrada en el mes de diciembre, a un $64,6 \%$ en la primera celebrada en el mes de febrero ${ }^{5}$, reducción importante si se toma en cuenta que del 2002 al 2010 el abstencionismo sólo se había reducido en aproximadamente cinco puntos (de $77,2 \%$ en 2002 a $72,1 \%$ en 2010).

\section{Cargos QUe deben lLenAR las elecciones MUNICIPALES}

En las elecciones municipales de febrero 2016 se presentó un récord en la cantidad de agrupaciones partidarias que postularon candidatos, ya que participaron 62, de las cuales 12 son partidos a escala nacional, 4 provinciales, 42 cantonales y 4 coaliciones cantonales; esta fue la cifra de participación político-partidaria más alta en la historia electoral costarricense (Zamora, 2016, p. 48).

\footnotetext{
${ }^{5}$ Ver http://www.tse.go.cr/pdf/elecciones/eleccionesmunicipalescifras.pdf
} 


\section{DERECHO EIECTORAL}

A fin de contrastar la cantidad de partidos que presentaron candidaturas en 2016, debe tenerse en cuenta que en la primera elección municipal del año 2002 participaron un total de 34 partidos políticos: 10 nacionales, 4 provinciales y 19 cantonales. Para el año 2006, fueron 45 los partidos participantes: 13 nacionales, 7 provinciales y 25 cantonales; y en el año 2010, un total de 47 partidos: 9 nacionales, 5 provinciales y cantonales (Zamora, 2016, p. 63), lo cual lleva a concluir que las últimas reformas legales aplicadas a estos procesos municipales también incidieron en una mayor participación de agrupaciones partidarias, sobre todo de partidos a escala cantonal que del 2002 al 2016 crecen en más de un 100\% (pasan de 19 a 42).

Consideramos que tener la posibilidad de financiamiento público para sufragar gastos derivados de la participación en estas justas resulta a todas luces un incentivo importante para motivar la participación partidaria, sin dejar de lado que en el nuevo Código Electoral se establecen requisitos menos rigurosos para la inscripción de partidos políticos; por ejemplo, el artículo 60 inciso e) exige solo 500 adhesiones para poder inscribir un partido a nivel cantonal ${ }^{6}$, requisito que en cantones con alta densidad poblacional no es difícil cumplir, pero sobre todo, lo que más ha facilitado el proceso de inscripción de partidos políticos es que se eliminó la obligación de realizar asambleas distritales, por lo que a nivel cantonal basta con hacer una asamblea cantonal abierta, que a su vez es la de mayor rango, para completar el proceso; mientras que en el pasado los interesados en inscribir un partido político debían realizar, obligatoriamente, una asamblea en cada distrito administrativo, para sacar los delegados a la respectiva asamblea cantonal.

Otro dato importante por resaltar de las votaciones de febrero 2016, es que ha sido la elección con la mayor cantidad de puestos a elegir, un total de 6069 según la tabla 2.

\footnotetext{
${ }^{6}$ El anterior Código Electoral disponía en el artículo 64 inciso e) que las adhesiones necesarias para inscribir un partido a nivel cantonal eran una cantidad equivalente al $1 \%$ de la población, aunque esa disposición fue anulada por la Sala Constitucional en resolución n. ${ }^{\circ} 2006-15960$ de las 14:53 horas del $1.0^{\circ}$ de noviembre del 2006, al considerar que infringía el artículo 33 de nuestra Carta Fundamental, pues en algunos casos ese $1 \%$ podría ser superior a las 3000 adhesiones que se exigían para inscribir un partido a escala cantonal.
} 


\section{DERECHO EIECTORAL}

Tabla 2

Cantidad y tipo de puestos por elegir, elecciones 2016

\begin{tabular}{l|l|r}
\multicolumn{2}{c|}{ Tipo de puesto } & Puestos a elegir \\
Alcalde & & 81 \\
\hline \multirow{2}{*}{ Vicealcalde primero } & Primero & 81 \\
& Segundo & 81 \\
\hline \multirow{2}{*}{ Regidores propietarios } & Propietarios & 505 \\
& Suplentes & 505 \\
\hline \multirow{2}{*}{ Síndicos } & Propietarios & 480 \\
& Suplentes & 480 \\
\hline \multirow{2}{*}{ Concejales de distrito } & Propietarios & 1888 \\
Concejales municipales & Suplentes & 1888 \\
distrito & Propietarios & 32 \\
\hline Intendentes & Suplentes & 32 \\
\hline Viceintendentes & & 8 \\
\hline \multicolumn{2}{r|}{ Total } & 6069 \\
\hline
\end{tabular}

Nota: Elaborado con base en información suministrada por el Departamento de Programas Electorales

Esa cantidad de puestos por elegir contrasta de manera exagerada con los puestos en disputa en una elección nacional, que son 60; toda vez que al haberse trasladado la elección de regidores junto con los demás cargos a nivel local, en las nacionales solo se eligen los cincuenta y siete escaños diputadiles más los tres puestos de la fórmula presidencial. Por consiguiente, en 2016, aparte de los regidores, se eligieron en la misma fecha los puestos de alcaldes y vicealcaldes, ambos en los 81 cantones existentes en ese momento, más los puestos de concejales de distrito en 472 distritos; intendente y viceintendente, así como concejales municipales de distrito en 8 distritos. Todos esos cargos de elección popular fueron creados por leyes de las últimas tres décadas (Zamora, 2016, p. 58).

Debido al número de partidos participantes y todos los puestos por elegir, también el proceso electoral de 2016 tuvo una cifra sin precedentes en la cantidad de candidaturas que se inscribieron; fueron 31879 las postulaciones registradas y debidamente aprobadas por la administración electoral, 16199 hombres $(50,81 \%)$ y las restantes 15680 mujeres $(49,19 \%)$ (Retana, 2016, p. 149). En la tabla 3 se presenta la distribución de las candidaturas inscritas por tipo de puesto. 


\section{DERECHOELECTORAL}

Tabla 3

Candidaturas inscritas por tipo de puesto, elecciones 2016

\begin{tabular}{l|r} 
Tipo de puesto & Candidaturas inscritas \\
\hline Alcaldías y vicealcaldías & 1780 \\
Regidores & 7015 \\
Síndicos & 6085 \\
Concejales de distrito & 16457 \\
Concejales municipales de distrito & 349 \\
Intendentes y viceintendentes & 103 \\
\hline TOTAL & $\mathbf{3 1} \mathbf{8 7 9}$ \\
\hline
\end{tabular}

Nota: Elaborado con base en información suministrada por el Departamento de Programas Electorales.

Con las cifras expuestas puede afirmarse, de manera contundente, que este fue el proceso electoral más complejo en toda la historia del TSE y que puso a prueba tanto su experiencia, como la capacidad demostrada, gracias a lo cual se logró exitosamente el objetivo de presentar al electorado la opción de elegir todos esos puestos, dentro de esa cantidad sin precedentes de candidatos. Lamentablemente, más del $50 \%$ de la ciudadanía no acudió a cumplir con su deber y derecho de ejercer el sufragio lo que, si bien sigue siendo una tarea pendiente para todos, es lo cierto que las reformas apuntadas brindan las herramientas necesarias para ir alcanzando mayores niveles de participación. Sin temor a equivocarnos, esa será la tónica de las futuras elecciones municipales, procesos sumamente complejos desde el punto de vista organizativo y logístico, pero con índices de abstencionismo superiores respecto a las elecciones nacionales.

\section{FORMA DE ELEGIR A LAS AUTORIDADES MUNICIPALES}

En nuestro país las circunscripciones electorales son las mismas circunscripciones territoriales. La Constitución Política, en su artículo 168, dispone una división administrativa con cuatro circunscripciones territoriales: a) territorio nacional; b) provincias; c) cantones, y d) distritos. Correspondientes a esos niveles territoriales, solo existen dos tipos de gobierno: el nacional y el local. (Jiménez y Obando, 2010, p. 23). Por su parte, el artículo 143 del Código Electoral señala que la división territorial administrativa se aplicará al proceso electoral. En este sentido, en el territorio nacional los puestos por elegir son los de presidente y vicepresidentes de la República. Cada provincia es una circunscripción 


\section{DERECHO ELECTORAL}

electoral en la que se eligen diputados a la Asamblea Legislativa, donde la cantidad de puestos dependerá del total de habitantes registrados en la correspondiente provincia, de acuerdo al último censo poblacional. Estos son los puestos que se eligen en elecciones nacionales, pero lo que ocupa nuestro interés en este momento son las restantes circunscripciones, concretamente, los cantones y los distritos administrativos.

De conformidad con el artículo 169 de nuestra Constitución Política, la administración de los intereses y servicios locales en cada cantón estará a cargo del Gobierno municipal (Aguilar, 2000, p. 32), que estará compuesto por un cuerpo deliberante, llamado concejo municipal e integrado por regidores y regidoras, así como por un funcionario ejecutivo, que es el alcalde. Por ende, además de los regidores, tanto propietarios como suplentes, en todos los cantones del país se elige un alcalde y dos vicealcaldes.

La cantidad de regidores por elegir en cada cantón la debe definir el TSE seis meses antes de la respectiva convocatoria a elecciones, con base tanto en la información que le suministre el Instituto Nacional de Estadística y Censos (Zamora, 2016, p. 53) como en los parámetros establecidos en el artículo 21 del Código Municipal, donde el mínimo es 5 y el máximo 13 (con igual cantidad de suplentes), dependiendo del porcentaje de la población total del país que habite en el cantón.

Cada distrito debe tener un concejo que, según el artículo 55 del Código Municipal, estará integrado por cinco miembros propietarios, pero uno de ellos será el síndico propietario referido en el artículo 172 de la Constitución Política, y cinco suplentes de los cuales uno será el síndico suplente establecido en el referido artículo constitucional (Zamora, 2016, p. 55).

Para 2016 se realizaron elecciones en 480 de los 481 distritos administrativos existentes para esas elecciones, es decir, solo en uno no hubo, ya que se trata de la Isla del Coco, donde no hay una población permanente (Zamora, 2016, p. 55). Hay dos tipos de órgano colegiado a nivel de distrito, dependiendo del distrito de que se trate. Solo en ocho distritos funciona a la fecha la figura denominada concejo municipal de distrito, concretamente, en Cervantes, Tucurrique, Monteverde, Cóbano, Lepanto, Paquera, Colorado y Peñas Blancas. En los restantes 472 lo que funciona es un concejo de distrito, pero como se indicó en todos los distritos, independientemente del órgano que funcione, se deben elegir, además del síndico, cuatro concejales propietarios y cuatro suplentes. 
De acuerdo con el artículo 54 del Código Municipal, los concejos de distrito serán los órganos encargados de vigilar la actividad municipal, promover la eficiencia de la actividad del sector público y velar por ella; sin embargo, carecen de autonomía para la ejecución de obras o servicios públicos, pues sus funciones solo involucran recomendaciones o informaciones al concejo municipal, por lo que no requieren de un funcionario ejecutivo. Cabe indicar que dentro de las funciones que el artículo 57 del mismo código señala para estos órganos están proponer a los beneficiarios de las becas de estudio, los bonos de vivienda y alimentación; recomendar al concejo municipal el orden de prioridad para ejecutar obras públicas en el distrito e informar semestralmente a la municipalidad del cantón a que pertenezcan, sobre el destino de los recursos asignados al distrito.

Los concejos municipales de distrito, por su parte, son órganos con autonomía funcional propia y competencias locales que les permiten, entre otras cosas, percibir directamente las tasas por los servicios distritales, siempre que sean asumidos por estos, así como tener participación en las patentes por las actividades efectuadas en el distrito y en los impuestos municipales, según se establece en los artículos 1, 4 y 9 de la Ley General de Concejos Municipales de Distrito, n. ${ }^{\circ} 8173^{7}$. Por tal motivo, los concejos municipales de distrito deben tener un órgano ejecutivo y de conformidad con el artículo 7 de dicha ley 8173, este será el intendente que también será elegido popularmente en la misma fecha, por igual período, con las mismas condiciones e iguales deberes y atribuciones que el alcalde municipal (Sandí y Víquez, 2014, p. 125). Además, de conformidad con el artículo 14 del Código Municipal -según la reforma introducida por la Ley 8611 del 12 de noviembre de 2007-, también debe elegirse un viceintendente, quien realizará las funciones administrativas y operativas

\footnotetext{
${ }^{7}$ Los Concejos Municipales de Distrito surgen de la necesidad de determinados distritos, alejados de la cabecera del cantón y con una realidad distinta a este último, de poder trabajar en forma independiente como si fueran "pequeñas municipalidades" y su creación data del 6 de julio de 1939, cuando se aprobó la Ley 118. Posteriormente, mediante Ley 4892, publicada en la Gaceta número 230 del 18 de noviembre de 1971, se incorporó el transitorio I del artículo 63 del Código Municipal de 1970, donde se dispuso que los concejos de distrito existentes antes de la vigencia de este Código Municipal, subsistirían bajo el nombre de "Concejos Municipales de Distrito", con la misma personalidad jurídica y con las mismas competencias que venían desarrollando. Se les cambió el nombre para no confundirlos con los "Concejos de Distrito" que se establecían en el propio artículo 63. No obstante, la Sala Constitucional, en sentencia n. ${ }^{\circ} 6000-94$ de las nueve horas y treinta y nueve minutos del 14 de octubre de 1994, determinó que resultaban inconstitucionales porque al establecerse que estos funcionan cual si fueran una municipalidad, se provoca una modificación contra legem de la división territorial, y que el transitorio I del artículo 63 del Código Municipal de 1970, al otorgarles un reconocimiento jurídico sin ninguna limitación en el tiempo, avala la creación de circunscripciones territoriales a las que se les reconoce, por la sola voluntad del Poder Ejecutivo, personalidad jurídica, aunado a que se les encarga la administración de los intereses y servicios locales, lo que quiere decir que se crean "nuevas municipalidades", sin observar el procedimiento que exige el artículo 168 de la Constitución Política. En definitiva, para legitimar jurídicamente a los concejos municipales de distrito, fue necesario reformar el numeral 172 constitucional, mediante Ley 8105 del 31 de mayo de 2001, para dar asidero a la figura (Jiménez y Obando, 2010, pp. 75 y 79).
} 


\section{DERECHO ELECTORAL}

que le asigne el intendente titular, al que deberá sustituir en sus ausencias temporales y definitivas (Zamora, 2016, p. 56).

Consideramos importante traer a colación que el concejo municipal de distrito es un órgano regulador a nivel constitucional, propiamente en el artículo 172, donde se dispone que se podrá crear para casos calificados y estará adscrito a la municipalidad, pero tendrá autonomía funcional propia. Asimismo, dispone que será una ley especial la que fije las condiciones en que pueden ser creados y lo relativo a su estructura, funcionamiento y financiamiento. En observancia a esa norma constitucional se promulgó la Ley General de Concejos Municipales de Distrito, n. ${ }^{\circ} 8173$ del 07 de diciembre de 2001, publicada en La Gaceta número 7 del 10 de enero de 2002.

Teniendo claro cuáles y cuántos puestos son los que deben elegirse a escala cantonal y distrital y considerando la amplia oferta partidaria que actualmente existe para acceder a esos puestos, es importante conocer cómo se adjudica cada uno de ellos. En este sentido, el artículo 202 del Código Electoral señala que tanto los alcaldes como los síndicos e intendentes serán elegidos por mayoría relativa de votos, es decir, resultará electa la nómina -que incluye a las respectivas vicealcadías y viceintendencias y suplencias- que más votos obtengan en la circunscripción, sea el cantón o el distrito, según corresponda. Los regidores, así como los concejales municipales de distrito y los concejales de distrito, serán elegidos por sistema proporcional, es decir, por cociente y subcociente, según lo dispone el numeral 201 del código de cita.

Resulta conveniente repasar brevemente el sistema proporcional previsto en nuestra legislación electoral. De acuerdo con los artículos 203 a 205 del Código Electoral, el cociente es la cifra resultante de dividir la votación total obtenida en la respectiva circunscripción -cantón o distrito que corresponda- entre el número plazas por llenar en esta, y subcociente será la mitad de esa cifra. El cociente es una cifra repartidora, por lo que un partido obtendrá tantas plazas como cocientes logre sacar; mientras que el subcociente sirve de umbral o límite para descartar de la repartición de escaños a los partidos cuya votación total sea inferior a esta cifra. Por ejemplo, si hay que elegir cuatro concejales y en el distrito los votos válidos de todos los partidos suman 100 000, entonces el cociente será 25000 . Si el partido A obtuvo 30000 votos, solo tendrá derecho a una plaza por cociente y le sobran 5000 votos, esa será su cifra residual o resto. Ahora, ¿cómo se llenan las otras plazas si ningún otro partido alcanzó la cifra cociente? Primero debe establecerse cuáles de los partidos restantes 


\section{DERECHO ELECTORAL}

superan el subcociente (12 500 votos), estos serán los que tienen derecho a optar por las plazas que falten por adjudicar; interpretando la ley, que su votación total se equipara a una cifra residual. Entonces, si al partido A le sobraron 5000 votos y hay tres partidos, B, C y D, cuya votación obtenida es de 15000,14000 y 13000 votos, respectivamente, votación que por lo dicho se concibe como cifra residual o resto, las plazas se repartirán dando prioridad al resto mayor, es decir, el $B$ es el primero al que se le debe adjudicar una plaza, luego al $C$ y después al $D$. El A no pudo obtener otra plaza debido que su cifra residual es la menor y ya no hay más plazas por llenar.

Debe tenerse en cuenta que, de conformidad con lo establecido por el artículo 148 del Código Electoral, solamente los partidos políticos inscritos pueden proponer candidatos a puestos de elección popular, lo que por supuesto incluye a todos los cargos municipales; es decir, una persona solo puede acceder a uno de esos cargos si un partido político, debidamente inscrito, ya sea a escala nacional, provincial o cantonal, lo propone como candidato. Además, para inscribir esa candidatura la persona postulada debe cumplir los requisitos que la legislación exige para ello como, por ejemplo, ser ciudadano en ejercicio, del estado seglar y estar inscrito electoralmente, cuando menos con dos años de antelación, en el cantón o distrito en que se quiera servir, entre otros, (artículos 15, 22, 56 y 58 del Código Municipal).

Otro aspecto importante por considerar para la inscripción de candidaturas, es que el citado artículo 148 del Código Electoral también establece que todas las nóminas de elección popular deben estar integradas en forma paritaria y alterna. Según el numeral 2 del mismo código, el principio de paridad implica que todas las nóminas de candidatos pares estarán integradas por un cincuenta por ciento $(50 \%)$ de mujeres y un cincuenta por ciento $(50 \%)$ de hombres y en las nóminas impares, la diferencia entre el total de hombres y mujeres no podrá ser superior a uno. La alternancia, de acuerdo a esa norma, significa que todas las nóminas de elección utilizarán el mecanismo mujer-hombre u hombre-mujer, de suerte que dos personas del mismo sexo no puedan estar en forma consecutiva en la nómina.

Las elecciones municipales llevadas a cabo en diciembre de 2010 fueron las primeras en que se aplicaron los referidos principios de paridad y alternancia para la participación política por género. En esa oportunidad 2373 mujeres (el $48,3 \%$ ) alcanzaron un puesto de elección popular a nivel municipal (Sandí y Viquez, 2014, p. 143); de estos, los cargos electos por el sistema 


\section{DERECHO EIECTORAL}

representativo, sean de regidores y concejales, son donde mejor se ha desempeñado esa paridad. En los cargos elegidos por el sistema mayoritario, la brecha entre hombres y mujeres permanece, según los resultados de alcaldías, vicealcaldías, sindicaturas, intendencias y viceintendencias (Zamora, 2016, p. 59). En efecto, en esas elecciones de 2010, para el caso específico de alcaldes, solo un $12,3 \%$ corresponde al sexo femenino y un $87,7 \%$ al masculino. En el caso de los síndicos fueron menos las mujeres electas para el puesto en propiedad, solo un $27,2 \%$; mientras que el $72,8 \%$ de los restantes puestos fueron adjudicados a hombres. La brecha en cuanto a los intendentes mantuvo la misma tónica, $75 \%$ hombres y solo un $25 \%$ mujeres (Sandí y Víquez, 2014, p. 159).

Esa brecha en materia de género, en lo que se refiere a los cargos electos por sistema mayoritario, no varió significativamente en las elecciones de 2016, pues de los 81 cantones, solo en 12 se eligió a una mujer como titular de la alcaldía; en los 69 restantes el puesto fue adjudicado a un hombre. En lo que se refiere a intendentes, si bien se dio una mejoría, no se alcanzó la paridad, pues de los ocho distritos, solo en tres el cargo se adjudicó a una mujer, en los otros cinco el puesto fue para un hombre. Por último, en cuanto a síndicos propietarios, en 306 distritos el puesto fue para un hombre y en 174 para una mujer 8 .

En resumen, es siguiendo todas estas reglas como se deben elegir todos los cargos a nivel municipal que son:

- Un alcalde y dos vicealcaldes en cada una de las municipalidades del país.

- Trece regidores propietarios y trece suplentes como máximo y como mínimo cinco en cada cantón.

- Un síndico propietario y un síndico suplente en cada distrito administrativo.

- Cuatro miembros propietarios y cuatro suplentes de los concejos de distrito, en cada distrito administrativo donde no exista un concejo municipal de distrito.

\footnotetext{
${ }^{8}$ Ver http://www.tse.go.cr/pdf/elecciones/eleccionesmunicipalescifras.pdf
} 


\section{DERECHO ELECTORAL}

- Cuatro miembros propietarios y cuatro suplentes en los concejos municipales de distrito de Tucurrique, Colorado, San Isidro de Peñas Blancas, Cóbano, Lepanto, Paquera, Monteverde y Cervantes.

- Un intendente y un viceintendente en los distritos donde exista un concejo municipal de distrito.

\section{VALORACIONES FINALES}

La posibilidad de elegir de manera directa a los principales responsables de dirigir los gobiernos locales sin duda alguna fortalece el sistema democrático de nuestro país y nos empodera como ciudadanos. Como hemos expuesto, esto no se dio de la noche a la mañana ni fue de fácil consecución, sino que durante décadas se fueron gestando las reformas constitucionales y legales necesarias para hacerlo realidad y darles la importancia y significado de contar con estos procesos.

A pesar del logro alcanzado y el contar con elecciones municipales a la mitad del período presidencial, que involucran la escogencia de todos los cargos existentes a escala cantonal y distrital, hasta ahora los porcentajes de participación registrados han sido muy pobres. Pareciera que los costarricenses las ven como elecciones de poca trascendencia, cuando lo cierto es que el desarrollo del cantón en cuanto a obra pública e infraestructura, así como la eficiencia en la prestación de los servicios públicos a cargo de las municipalidades, dependen en un alto grado de las decisiones de sus principales autoridades, todas de elección popular.

Es innegable que como ciudadanos tenemos la responsabilidad de informarnos sobre quiénes se están postulando para esos puestos; cuál es su propuesta, su hoja de vida; entre otras cosas, con el fin de elegir a aquellos que evidencien ser los idóneos. Es nuestra responsabilidad realizar un voto informado, pues si somos electores es porque radicamos en el distrito y cantón donde la municipalidad ejerce su jurisdicción e, indiscutiblemente, las decisiones que vayan a tomar los responsables de ejercer los puestos en disputa nos van a afectar positiva o negativamente, ya sea de manera directa, desde la prestación de servicios básicos como la recolección de basura hasta la aspiración de ver satisfechos, en el menor tiempo posible, nuestro interés en obtener los permisos respectivos para realizar una construcción, una remodelación de nuestra casa o ejercer determinada actividad económica; o bien, de manera indirecta, mediante la adecuada recaudación y manejo de los tributos municipales. 


\section{DERECHO EIECTORAL}

A pesar de lo anterior, en las tres primeras elecciones municipales celebradas, casi el $80 \%$ de los electores inscritos en el padrón no acudió a las urnas, lo que motivó la realización de una serie de cambios a nivel legal, para fortalecer estos comicios y propiciar una mayor participación de la ciudadanía. Las últimas elecciones de este tipo celebradas en 2016 incorporaron todas las mejoras concebidas a través de reformas legales: realizarse dos años después de las nacionales, tener financiamiento estatal y concentrar todos los cargos a nivel local; esto pudo haber incidido en la mejoría mostrada en los niveles de participación, pero todavía dista de lo que un proceso de esta naturaleza requiere. Si queremos servicios de primer mundo debemos empoderarnos y conseguirlos a través de nuestra participación en democracia, por lo menos en las justas electorales, para brindarle verdadera legitimidad al mandato de quienes resulten electos, y hacer realidad que la mayoría de los ciudadanos estemos representados por las autoridades electas.

Es muy pronto para saber si los últimos cambios introducidos en la escogencia de las autoridades municipales serán suficientes para cumplir el cometido de fortalecer la participación de esos procesos electorales; pero a todas luces es un reto país lograr que todos los costarricenses concienticen sobre la responsabilidad e importancia que tiene su voto en la elección de estas autoridades.

\section{REFERENCIAS BIBLIOGRÁFICAS}

Aguilar, O. (2000). Análisis de los Elementos Presentes en el Código Municipal de 1998 en relación con la Elección Popular del Alcalde (Tesis de licenciatura). Universidad de Costa Rica, San José, Costa Rica.

Costa Rica (2009). Código Electoral. Recuperado de http//www.tse.go.cr/pdf/ normativa/codigoelectoral.pdf

Costa Rica (1998). Código Municipal. Recuperado de http//www.tse.go.cr/pdf/ normativa /codigomunicipal.pdf

Costa Rica (1949). Constitución Política. Recuperado de http//www.tse.go.cr/ pdf/normativa/constitución.pdf

Costa Rica. Tribunal Supremo de Elecciones (2005). Atlas Electoral. Recuperado de http://atlaselectoral.tse.go.cr 


\section{DERECHO EIECTORAL}

Costa Rica. Tribunal Superno de Elecciones (2014). Elecciones en Cifras 19532014. Recuperado de http://www.tse.go.cr/pdf/elecciones/ eleccionescifras.pdf

Costa Rica. Tribunal Superno de Elecciones (2016). Elecciones Municipales en Cifras 2002-2016. Recuperado de http://www.tse.go.cr/pdf/elecciones/ eleccionesmunicipalescifras.pdf

Echeverría, J. (Ene.-Jun., 2016). Trascendencia política de las elecciones municipales. Revista de Derecho Electoral, (21), 5-19.

Espinosa R., Estrada V., Gómez S. y Jiménez L. E. (2003). Las Elecciones de Alcalde y el Sistema Democrático: Percepciones y Expectativas de la Población Costarricense. En Rodríguez, F. y Zeledón, F. (Editores). Elección en las alcaldías 2002 ¿una nueva esperanza democrática? San José, C.R.: Fundación Friedrich Ebert, pp. 27-28.

Jiménez Castillo A. y Obando Vives V. (2010). Alcances del actuar de los Concejos Municipales de Distrito en relación con la autonomía funcional otorgada por el ordenamiento jurídico costarricense (Tesis de licenciatura). Universidad de Costa Rica, San José, Costa Rica.

Mora Arias J. N. (1999). La Figura del Alcalde en el Actual Régimen Municipal Costarricense (Tesis de licenciatura). Universidad Panamericana, San José, Costa Rica.

Retana, L. (Jul.-Dic., 2016). Elecciones municipales 2016: Una breve aproximación. Revista de Derecho Electoral, (22), 149-160

Rodríguez, F. y Zeledón, F. (Editores). Elección en las alcaldías 2002 cuna nueva esperanza democrática? San José, C.R.: Fundación Friedrich Ebert.

Sandí, N. y Víquez, S. (2014). Proceso de Redefinición de las Elecciones Municipales a la Luz del Nuevo Código Municipal y el Nuevo Código Electoral (Tesis de licenciatura). Universidad de Costa Rica, San José, Costa Rica.

Sobrado, L. (2011). Descentralización y Reforma Electoral. En Ideario sobre la descentralización en Costa Rica. San José, C.R.: UNED-IFAM, pp. 144-147.

Tribunal Supremo de Elecciones (2001). Resolución n. ${ }^{\circ}$ 1734-E-2001 de las 08:45 horas del 24 de agosto.

Tribunal Supremo de Elecciones (2008). Resolución n. 405-E8-2008 de las 07:20 horas del 8 de febrero.

Zamora, E. (Ene.-Jun., 2016). De 1813 a 2016: 202 años de elecciones municipales. Revista de Derecho Electoral, (21), 48-68. 


\section{DERECHO ELECTORAL}

PRIMER SEMESTRE 2019 NÚMERO 27

Zeledón, F. (2003). Siembra Vientos: Las Primeras Elecciones Directas de Alcaldes en Costa Rica, lo Municipal y las Tendencias en la Cultura Político Social. En Rodríguez, F. y Zeledón, F. (Editores). Elección en las alcaldías 2002 ¿una nueva esperanza democrática? San José, C.R.: Fundación Friedrich Ebert 